\title{
Peer support in mental health: a narrative Review of its relevance to social work
}

Malcolm Payne, Emeritus Professor Manchester Metropolitan University 23 Sandpiper Road, Cheam Sutton SM1 2ZU, UK 


\section{Abstract:}

This paper reviews definitions of, and commentary and research on peer support as a strategy in mental health service provision, summarizing areas of relevance to social work practice. It is a well-established in many countries, linked to the recovery movement. It provides peers to support people recovering from mental illness, seeing the personal and social journeys of people through mental illness as important aspects of improving their quality of life, accepting some social disability. It is connected with self-help, informal caregiver and advocacy movements and feminist ideas about treatment. Research reviews demonstrate that employing peers as supporters for people recovering from mental ill-health is feasible both in peer-led and in professional mental health provision. Outcomes are at least as good as professional help and peer support reduces use of expensive in-patient services. Positive features of the relationships between peers and patients brings benefits to both, building positive experiences in patients' lives and helping them manage disabilities.

\section{Acknowledgements}

This paper is based on a project for the Sutton Mental Health Foundation, UK, carried out in 2017 and part-financed by the European Union ERASMUS Programme, through an association with the Sts Cyril and Methodius Faculty of Theology, Palacký University of Olomouc and the CARITAS School of Social Work, Olomouc, Czech Republic

\section{Introduction: what is peer support?}

This paper reviews research and commentary on peer support as a strategy in mental health service provision and in doing so examines its relevance to social work provision and practice. 'Peer' is a widely-used term in social science referring to people who are of equal status or who share characteristics that makes them similar in important respects. Those shared characteristics may allow a peer to be more influential than an authority figure in people's lives.

Solomon (2004: 397) defined peers in mental health services as people with experience of the mental health service delivery system, who are emotionally and psychologically stable and not currently a substance user or dependent on substances such as alcohol or drugs. This proposes that the major factor in achieving influence 
with people recovering from mental health services is their experience in coping with problems presented by the service system. Focusing on the shared experience of mental ill-health, however, neglects other peer characteristics, such as age, ethnicity, gender or social class, which may potentially also be significant factors in generating or detracting from peer engagement.

\section{Peer support in mental health and education}

Peer support is a well-established approach to, and element of, providing mental health services in many countries. Solomon's (2004: 393-4) conceptual review identifies six types of peer support provision in mental health services:

- self-help groups. These are small group structures for mutual aid, formed by peers to assist them in satisfying a common need or overcoming a common difficulty and bringing about desired change.

- online or Internet support groups, where communication is online rather than face-to-face.

- peer-delivered services. These are provided by people who identify themselves as having experienced mental illness or receiving mental health services and provide services for peers.

- peer-operated services are planned, operated and administered by peers.

- peer partnerships. In these services, peer-operated services share control of the services with other mental health service providers, such as hospitals, clinics and community health or social care providers.

- peer employees, who occupy positions within mental health services where employment is restricted to peers.

This range of provision offers opportunities to social workers in engaging peers in a variety of ways relevant to local services.

Peer support is sometimes seen as a 'sheltered environment' or as an 'apprenticeship' (Watts \& Higgins, 2017: chs 11 \& 13). So, it could provide opportunities for people to gather qualities such as courage, resolve and strength to enable them to enter a wider social context, taking their place in society. 
Descriptions of peer support show how it aims to be nonhierarchical and is a matter of choice, since it is accepted that it may not be useful for everyone. The approach is contrasted with treatment processes in which the lead is taken 'experts' in defining the issues to be tackled in people's lives. Peer support does not, however, oppose treatment or psychiatry although it seeks to avoid the professional focus and language of diagnosis and treatment. It is, rather, a valid adjunct to formal mental health provision concentrating on struggles with problems of living; this makes it very relevant to social work. Sharing experiences with peers helps to identify stages of a hopeful journey through setbacks and takes joint ownership of initiatives to take risks along the road to recovery. (Watts \& Higgins, 2017: ch 13).

Another important aspect of peer support is to enable people to experience a sense of connection to others. Illness often takes people outside the time frame of normal lives in their families and communities. This leaves them alone in a 'frozen present' (Browne 2008) to 'get better' before becoming part of the cycles of events and plans that are part of the lives of other people around them. Through peer support, service users continue at least some of their normal life.

\section{Recovery and the recovery movement}

In a series of evidence reviews of peer support, Davidson and colleagues (Davidson et al, 1999; 2006; 2012) associate peer support with the 'recovery movement'. This is the US term for what is also called the 'survivor' or 'ex-patient' movements. Such ideas have been part of mental health activism influencing American mental health services during the 1980s and 1990s (Adame and Leitner, 2008). Many Western governments, including Ireland, New Zealand, the UK and the USA, developed policies favouring recovery in the $21^{\text {st }}$ Century (Watts \& Higgins, 2017).

Within the recovery movement, peer support contests 'professional centrism' (Watts and Higgins, 2017: ch 4), which gives the greatest importance in recovery to medical, nursing and social treatment and care. This stance sees patients as developing illness, receiving treatment, with their condition improving or being cured. Future episodes of illness as seen as relapses, leading to the need for further professional interventions. By contrast, recovery perspectives focus on the whole life experiences of people with mental illnesses and social and community reactions to changes in their wellness and 
illness. The personal and social journeys of people with mental illnesses, and interventions that focus on them, are as important as illness and treatment. These conceptions place recovery as a relevant idea for guiding social work practice.

Recovery from mental illness implies moving towards or achieving a mental state that someone prefers to their condition of illness, and looks back to past attainments. It contrasts, however, with the assumption in psychiatry in the early $20^{\text {th }}$ century that complete recovery (a preferred or favoured end state) from major or psychotic mental illness was not possible. Later experience and research found that individuals improved at least in the remission of symptoms and sometimes in decreased use of medication. Often, social disabilities also declined so that living independently and working became possible for many (McCranie, 2010: 473-4). Recovery thus became associated with improvements in at least some aspects of the quality of life.

The recovery movement focused on an individual's lived experience in accepting and overcoming social disabilities created by the condition (Deegan, 1988). This includes both short-term and longer-term disabling factors in the personal psychological reactions, social life and relationships of people who have experienced mental illness. These areas all form relevant locations for social work practice. This view of recovery from mental illness saw it as a process by which people gained personal experience of a new state and capacity to function in society. Recovery may nevertheless also connect with the experience of regaining something lost.

Seeing recovery as a process through which people move contests a therapeutic or medical view of recovery as treatment coming from an external source leading to a cure. During the recovery process, people use their internal resources to acknowledge being socially disabled but nevertheless move towards achieving a new sense of self (Deegan, 1995). This might include '...the development of new meaning and purpose in one's life as one grows beyond the catastrophic effects of mental illness.' (Anthony, 1993: 527).

Leamy et al's (2011) conceptual review of the literature isolates characteristics of the recovery journey from a wide range of literature. Recovery is an active, individual, gradual and non-linear process of trial and error, a journey in which there are stages and much struggle, 
multidimensional in the issues tackled. It is a life-changing but not curative process. Supportive and healing environments help recovery, but can occur without professional intervention. Five types of intervention are helpful:

- promoting connectedness.

- promoting hope and optimism about the future.

- promoting a positive sense of identity.

- identifying meaning in life and mental illness experiences.

- empowerment in achieving personal responsibility and control over life and focusing on strengths.

Tew et al's (2012) literature review of social factors in recovery from mental illness identifies the importance of working with families and communities. They suggest this forms a proactive agenda for mental health practice in social work. Frost et al's (2017) review of the literature attempts makes a helpful distinction between psychosocial intervention and rehabilitation aims in setting service requirements for an integrated recovery-oriented service:

- psychosocial interventions promote hope, recovery, selfagency and social inclusion.

- rehabilitation interventions achieve improvements in daily functioning, working with the service user on restoration of skills and competencies and active community reconnection.

This recent professional analysis incorporates recovery movement ideas into service planning and management for both professional and user-led mental health services and brings forward the importance of the social as an aspect of mental health.

\section{Professional and service development}

Humane ideals of 'moral treatment' came to influence mental health treatment, through reform movements in the 1840s, which followed a general trend towards setting up institutions for the care of many groups of people which reached its peak during the early $20^{\text {th }}$ century (Porter, 1987). Policies of 'moral management' promoted by the professionalisation and medicalisation of the treatment of mentally ill people led to a preoccupation with achieving regimes of docile, routinized living in these institutions, the asylums. Jones (1993) characterises the development of policy as a struggle between medicine and the law for control of the field. Unsworth (1979) and Ramon (1985) propose that a social science view incorporating the 
importance of social relationships also had influence in the $20^{\text {th }}$ century, as the tide of institutionalisation receded and led to a reversal of policy towards 'community care' in smaller, shorter-stay institutions. Unsworth argued that legal, medical and social professions representing different views began to contest for influence on how treatment and services should develop.

Community care policies led to a significant movement to close the asylums. An international trend in the 1980s, in both learning disability and mental health services (Brown, 1985), began to lead to the development of a wider range of services based in the community in small and non-institutionalised settings or provided by non-professional services and transferring patients into 'ordinary housing' in community settings (Bayliss, 1987).

An important development in the 1980s was the UK government's 'Care in the Community' Programme, which financed development projects across the country to facilitate discharge of patients from large institutions still caring for large numbers of people with mental illnesses or learning disabilities. Research into these projects (Renshaw et al, 1988; Knapp, 1992) sought to identify methods of social support for service users. Projects took different approaches, but initial support included provision for multidisciplinary individualised care planning and subsequently for services to be channelled to individual service users through a key care worker (Renshaw et al, 1988: 67-8). Sometimes this was preceded by rehabilitation involving a structured training programme in living skills (Renshaw et al, 1988: 122-3). Locations for services included a local resource centre, or out-of-hours teams supporting day-time workers. Support services included work experience placements, leisure and recreational activities, independent living training and home teaching. A range of residential accommodation, day care and professional support was provided. Formal education classes both as part of ordinary provision and separately were used (Renshaw et al, 1988: 138; Knapp et al, 1992: 173-5). Attempts were made to use ordinary local facilities as much as possible (Renshaw et al, 1988: 143). Support for carers and families of service users and for project workers was also an element of many of the projects.

A connected project providing 'neighbourhood support units' was also evaluated. This classified support worker activities into: 
- Personal care.

- Emotional care.

- Domestic activities.

- Errands, such as shopping and paying bills.

- Non-routine or one-off tasks 'anything that keeps them going' (Warren, 1994).

All of these developments engaged social work professionals as an important part of mental health community provision.

In summary, we have seen that medicalisation and professionalisation of services developed in large institutions which, though more humane, engendered docile and routinized behaviour, which could often be unhelpful and dependency-creating. A shift into communitybased, less institutionalised care in the mid to late $20^{\text {th }}$ century led to development of a range of services to support more ordinary lifestyles. The history of these changes reflected discourses between medical, legal and social interpretations of the needs of mentally ill people, within the context of social services for adults with long-term care needs. Into these professional discourses about mental illness, the recovery movement emerged, seeing former patients as survivors of unhelpful professional treatment regimes.

\section{Advocacy, user and informal care movements and feminism}

Peer support and the recovery movement in mental health developed alongside and was intertwined with three other developments in thinking during the 1980s and 1990s:

- The self-help movement, also described as mutual aid.

- A movement to value and informal and family caregivers.

- Advocacy movements, seeking to facilitate users and carers in advocating for their needs within official decision-making systems.

At the same time, feminist thinking was having an important impact on thinking about caring roles were conceived both politically and morally. Social workers were strongly involved in all four of these development as they contributed to mental health provision.

\section{Self-help and mutual aid}

The focus on the self-help movement of the 1970s was to encourage the development of social provision by agencies employing non-professional staff. Self-help also reflects a distinctive ideology, based on a view of the value of participatory engagement helps to 
encourage people to become involved and discourages relapse (Gartner and Reissman, 1977: 115-7). An important underlying concept was normalisation (Wolfensberger, 1972; Brown and Smith, 1992; Race, 2003), developed as 'social role valorisation' in the learning disability field. This concept involved offering people in residential settings experience in carrying out valued social roles, such as helping others and participating in decision-making processes, so that they could be helped to develop lifestyles as close as possible to ways of living valued by most people. Ramon (1989) argued that this policy also involved changing professional and public attitudes to the capacity of people recovering from and living with disabilities and illnesses to live a satisfying independent life.

Early research into self-help groups established the finding that group members were helped by peer support. Stigmatised groups benefited from reinforcement of their identity and acceptance within a social group despite behaviour problems that excluded them from ordinary social involvement. Being active in working on their problems was also empowering, whereas professional services often generated passive behaviour (Gartner \& Reissman, 1977: 97-9). An important mechanism that generated this positive finding was the 'helpertherapy' principle that people who help are helped most (Gartner \& Riessman, 1977: 99-107). This was thought to be because helpers:

- Experience an increase in a sense of personal competence, because they made a useful contribution - 'I must be well if I can help others'.

- Value a sense of equality in both giving and taking as part of the service.

- Gain valuable personal learning from their helping relationships.

- Receive social approval from helping.

A further important factor is the engagement of consumers as producers of the service, which draws on the reality that successful human service depends on the involvement and motivation of the consumers. In recent years, co-production has been an important policy emphasis in health and social care provision (Hunter \& Ritchie, 2007). 


\section{Movements for informal caregivers}

The shift towards community care of people with long-term care needs during the 1980s increasingly highlighted the role of carers who were neighbours, friends or family members of people with care needs (Qureshi et al, 1989). Community care policy increasingly saw service users as being cared for by people within the community as well as in the community, and a need for carers' contributions to be interweaved with formal services (Bayley, 1973). Attempts to set up neighbourhood care services by local volunteers were researched and the definitive findings that these could not substitute for formal public provision led to a move away from attempts to promote such provision (Abrams et al, 1989).

Relatives and especially spouses provide most informal care (Bulmer, 1987); friends are less important (Willmott, 1986). Family care may be problematic, however, because people's kinship networks vary. Willmott (1986) distinguished families that had large numbers of relatives living locally, from extended families where there were many connections, but people lived at a distance and from others where there was only occasional contact. Some people had only residual networks, where there was little contact. Evidence developed of stress on family and other carers' resilience, health and family finances of caring for mentally ill people (Perring et al, 1990); and this was also found among other groups of carers.

\section{Advocacy}

During the 1980s, advocacy became an important movement supporting participation by service users in decisions about their care (McDonald, 2006: 111-2). Citizen advocacy involved volunteers recruited to befriend and understand the views of someone who cannot speak for themselves because of learning or physical disabilities or mental illness. Self-advocacy provided training and group support to enable service users to learn the skills and gain the emotional strength to advocate for themselves. Group advocacy brought together people with similar interests who could work together to advocate for their shared needs. Brandon et al (1995: 103-18) also identified peer advocacy, with a long history in psychiatry, associated with peer support and provided by 'survivors of the system' rather than the volunteers of citizen advocacy. They describe sponsorship, interceding with aggrieved employers, the police or other people with 
whom service users might have difficulty in presenting their needs, and mentoring.

\section{Feminist and ethics of care positions and professional empathy}

Another important set of concepts emerged in feminist thinking. Important elements of feminist helping techniques focus on dialogue between equals. The focus on human connectedness which emerges from the feminist ethics of care position is an important aspect of the narrative of collaboration among consumers and professionals in mental health services (Proctor et al, 2014). Such views propose that only personal experience creates knowledge about many social aspects of life. It offers an advantage in understanding and describing emotional and social positions. Only experiencing oppression or stigmatisation, therefore, offers a full understanding of the social experience of it. Empathy from professionals is not enough. It follows that, in democratic societies, professionals and governments should organise services to enable the expression of that special understanding, and, having heard that understanding, should respond to it in the way services are provided (Payne, 2014: 59-60).

\section{Research on peer support \\ Overview}

Davidson's et al's (2012) review of research and commentary, building upon earlier reviews from these authors, identified three aspects of research:

- Feasibility studies demonstrate the possibility of employing people recovering from mental illness who could function as peer supporters of others in the same position. Studies internationally show that this is feasible, with many benefits both for service users and peer workers, but care is required in incorporating peer support in the mental health service system (Davidson et al, 1999, 2006; 2012).

- Comparison studies demonstrate that peer supporters functioned as least as well as non-peer staff with comparable outcomes (Davidson et al, 1999, 2006).

- Relationship studies sought to identify unique features of the relationship between peer supporters and recipients of support.

Davidson et al's (2006) systematic study supported the feasibility findings, but found it hard to differentiate peer from nonpeer interventions. Two studies in their analysis found that peers could 
forge successful relationships with otherwise hard-to-engage service users. They helped by increasing hope, modelling adaptive problemsolving, and demonstrating the benefits of participation in treatment and rehabilitation. Another aspect of their support was by helping service users to take part in leisure and social activities other than employment.

Trachtenberg et al's (2013) systematic review found that, despite methodological problems with the specification of peer support interventions and the cost-benefit analyses undertaken, there was considerable evidence that properly trained and supported peer workers in mental health teams had a positive impact on high-cost interventions. This was true in comparisons with in-patient care. The gains were not only financial, because the poor quality of costly inpatient care means that economical interventions that avoided it were beneficial to patients.

Chinman et al's (2014) systematic review of 20 studies of peer support services found moderate evidence that peer support workers reduced use of in-patient services and improved many recovery outcomes. Stubbs et al's very recent (2016) systematic review of peer support interventions in severe mental illness found only three studies that met robust methodological criteria. While feedback on interventions had been good, the range and poor definition of interventions made it hard to determine their effectiveness. Also, the criteria for successful outcomes were improvements in physical health, lifestyle and reduction in patients' use of medical appointments. These, however, are professional service objectives rather than aims associated with the 'recovery' objectives that are given priority in the peer support literature.

While all these findings are positive, they suggest that greater attention needs to be given to how to implement peer support effectively within services.

New roles identified in relationship studies, the third type of research identified by Davidson at al (2012), identified success in two areas, and begins to build towards greater clarity in implementation. One was advocacy within mental health and other service systems on behalf of peers. The other, related to this, was in identifying and making connections within other areas of community support, such as 
employment, housing or building personal relationships within the community.

\section{Managing peer support in professional mental health services}

These research findings supporting the value of peer support but identifying lack of clarity in how to implement have led to work on how to intervene in and manage services to make use of peer support. Some recent literature is concerned with the practicalities and problems of employing peer support workers in professional services, rather than in the 'pure' form of peer-led services. Repper and Carter's (2010, 2011) comprehensive review of studies found that employing peer support workers (PSWs) can lead to a reduction in admissions and numerous improvements in the lives of people with mental health problems. They have the potential to drive a stronger recovery focus in services. The challenges in developing of peer support lay in devising effective training, supervision and management of all involved. Similar findings arose from the Scottish evaluation of peer support pilot schemes in a variety of services (McClean, et al, 2009). Repper's (2013a) study of appointing peer support workers in mental health service organisations identified four areas of organisational change required:

- Preparation of the organisation, teams hosting the workers, defining roles, clearing up common myths and misperceptions and developing job descriptions and person specifications

- Recruitment processes, including supporting people who were not offered posts. This is important because potential peer support employees may have become committed to the peer support process through their own experience as mental health service users. Consequently, the disappointment and personal consequences of not being appointed may be considerable.

- Employing the workers involved selecting suitable placements, indication and orientation, regular supervision and support and maintaining the well-being of the peer support worker.

- On-going development of the role involved identifying future carer pathways, training opportunities and thinking about and implementing further organisational change.

An example of useful organisational developments was a culture conflict between a health service organisation and the recovery philosophy. The organisation required all mental health staff to 
undergo 'control and restraint' training, to be able to manage dangerous behaviour among patients. The recovery philosophy went against taking part in restraint or in forced use of medication. A philosophy of 'no force first' was developed for peer support workers, and this was negotiated with other staff. Consequently, all staff began to adopt a policy of avoiding unnecessary restraint.

\section{Outcomes for service users}

Despite the management difficulties of developing peer support as part of mental health services, several studies and evaluations demonstrate successful outcomes of peer support provision, in addition to the general studies discussed above demonstrating feasibility.

Among these, Simpson \& House's (2002) systematic review found that involving users as employees of mental health services led to service users having greater satisfaction with their personal circumstances and less hospitalisation. Providers of services who had been trained by users had more positive attitudes toward users. Service users reported being less satisfied with services during evaluation studies when interviewed by other users, suggesting that more critical opinion was disclosed to them, compared with non-user interviewers. Pfeiffer et al's (2011) systematic review of the efficacy of peer support interventions for depression found that peer support was more effective than the 'usual care' in reducing depressive symptoms and as good as cognitive behavioural therapy, which is usually seen as the 'talking' therapy of choice for depression.

Lawn et al's (2008) case study evaluated the introduction of peer support 'packages' on discharge from mental hospital. It concluded that this was an effective adjunct to mainstream mental health services. There were personal benefits to consumers and peers, cost savings, and potential for encouraging mental health service culture and practice to move towards a greater recovery focus and improved collaboration with general practitioners.

Well-conducted smaller case studies include Sledge et al's (2011) random-controlled trial compared hospital readmission rates were reduced and length of subsequent stay in hospital also reduced where peer mentors were allocated to people discharged from mental hospital. Chakkalackal \& Kalathil (2014) evaluated three peer support groups for people with dementia in extra-care housing in London. 
Well-being scores improved, although independent living skills did not improve: perhaps the level of service users' existing frailty meant that this was unlikely in any case. Participants' perceived social support and memory recall improved: they felt more supported and less lonely than they had expected. They learned ways of managing their memory, communication and lives better. Family members also felt that participants communicated better. Because of these changes, participation in social activity around the housing schemes improved and social groups were more sustainable. This study demonstrates that groups with specific learning objectives may achieve progress in social relationships even if physical improvements in health and disability are impossible.

In summary, studies showed that including peer support workers in mental health provision generated benefits for the peer worker, who achieved greater confidence in their own recovery journey, a more positive sense of identity, felt less stigmatised and more skilled. For people being supported, the benefits were increased self-esteem and confidence, improved problem-solving skills, increased sense of empowerment, improved access to work and education, more friends, better relationships, more confidence in social settings, greater feelings of being accepted, understood and liked, reduced self-stigmatisation, greater hopefulness about their potential and more positive feelings about the future. In the UK, the experience of in-patient care has consistently been poor, and adding peer support may help to improve that, as Pfeiffer et al's (2011) systematic study of peer support in depression which, we saw above, outperformed 'usual care'. Benefits to the organisation include an improved recovery focus and a challenge to negative staff attitudes, and improved and more flexible employment and staff support processes.

\section{Discussion}

This discussion draws together the main points of this review and suggests how social work provision and practice might intervene to bring the benefits of peer support in mental health services. Interventions identified as supportive that social work could help peer support workers offer are: 
- Building a reciprocal and equal relationship, so demonstrating how to achieve this with others and building confidence and skills in asking for and accepting help.

- Expecting and modelling 'well' behaviour and successful relationships.

- Helping service users plan and rehearse behaviours to build, rebuild or replace relationships with others in their family and community.

- Enable service users to recognise and respond helpfully to symptoms and experiences associated with their illness.

- Enabling service users to learn by relating to and comparing themselves with a respected model.

- Proposing, discussing and applying clear limits to and requirements for specific behaviours.

- Making it clear that you will respond to protect service users if they experience difficulties.

- Pointing to demonstrations in users' lives that they are important to others, making explicit the self-esteem, belonging and companionship that results.

- Identifying and clarifying the availability of emotionally sustaining help from significant others in their lives and practical assistance with coping with daily living from peers.

- Giving direct guidance and advice in practical matters, including finding financial help.

- When service users feel unable to cope with relationships or activities, making sure support workers are alerted to problems, demonstrating awareness of depleted energy and resilience, finding substitute services or help for whatever is problematic and planning how they can move towards managing difficulties in the long-term.

- Enabling service users to discuss freely troubling problems and their feelings about those problems.

- Identifying adverse reactions of past behaviour and advising and rehearsing changes that would modify these adverse reactions.

- Helping to live with the consequences of a long-term disabling condition. 
- Assuring service users of your interest and concern and of their right to help.

- Encouragement and praise, validating their progress through the recovery journey by showing that you value their efforts and are confident in their ability.

- Encouraging and facilitating involvement with new education, leisure and work activities to help build new or renewed social networks.

General social strategies that services can use to boost recovery and peer support include:

- Education for service users, family member and service provider staff about recovery and peer support.

- Services for carers, including respite care.

- Service user and family involvement in service provision and management.

- User-run and user-controlled alternatives in service provision.

- A focus on relapse prevention.

- Crisis planning and advance planning in the event of difficulties.

- Commissioning and financing that enhance peer support strategies.

- Systems to measure outcomes and compare them with 'usual service'.

- Revise policy to facilitate recovery and peer support.

- Identify and pursue opportunities for stigma reduction.

While service evaluations of and feedback on peer support provision is positive, robust comparative research is relatively limited. There is evidence that hospital readmission rates and length of hospital stay are reduced if peer support is provided, and that peer support is better than or comparable with 'usual care'. It was also a useful adjunct to conventional provision. Both peer support workers and service users benefited.

\section{Conclusion}

Peer support is a well-established approach in mental health and many other areas of health and social care. Research and evaluation has demonstrated it to be a feasible and successful element within, and alternative to, conventional treatment and service 
provision. It is associated with movements for service user and caregiver involvement in decision-making and planning in health and social care service provision, in particular the recovery movement. These movements emerged from dissatisfaction with the professionalisation of health and social care and managerialism in public services during the 1970s and '80s. Assimilating peer support into professional provision for mental health is therefore in some ways inconsistent with the focus in psychiatry and healthcare generally on refining treatment objectives within professional interventions. Peer support is, instead, more concerned with building positive experiences in service users' lives as they manage continuing disabilities that arise from their condition in the networks of relationships available in their families and communities. This makes it a valid focus for social work roles in mental health services.

While the ideology of recovery and peer support is established, social interventions such as these are not well-articulated in healthcare. There is, however, a body of commentary and experience which clarifies the nature of support and appropriate elements and organisation of peer support services in mental health and elsewhere. Research in the future would benefit from clarification and testing of peer support interventions and peer-led service provision or the role of peer partnerships in mental health provision.

\section{References}

Abrams, P., Abrams, S., Humphrey, R. \& Snaith, R. (1989) Neighbourhood Care and Social Policy. London: HMSO.

Adame, A. L. \& Leitner, L. M (2008) Breaking out of the mainstream: the evolution of peer support alternatives to the mental health system. Ethical Human Psychology and Psychiatry. 10: 146-62.

Anthony, W. A. (1993) Recovery from mental illness: the guiding vision of the mental health service system in the 1990s. Psychosocial Rehabilitation Journal. 16: 521-37.

Bayley, M. (1973) Mental Handicap and Community Care: A study of mentally handicapped people in Sheffield. London: Routledge and Kegan Paul.

Bayliss, E. (1987) Housing: The foundation of community care. London: National Federation of Housing Associations.

Brandon, D., Brandon, A. \& Brandon, T. (1995) Advocacy: Power to People with Disabilities. Birmingham: Venture. 
Brown, H. \& Smith, H. (eds)(1992) Normalisation: A Reader for the Nineties. London: Routledge.

Brown, P. (1985) The Transfer of Care: Psychiatric deinstitutionalization and its aftermath. New York: Routledge.

Browne, I. (2008) Music and Madness. Cork: Cork University Press. Bulmer, M. (1987) The Social Basis of Community Care. London: Allen and Unwin.

Chakkalackal, L.\& Kalathil, J. (2014) Peer Support Groups to Facilitate Self-Help Coping Strategies for People with dementia in Extra-Care Housing. London: Mental Health Foundation.

Chinman, M., George, P., Dougherty, R. H., Daniels, A. S., Ghose, S. S., Swift, A. \& Delphin-Rittmon, M. E. (2014) Peer support services for individuals with serious mental illnesses: assessing the evidence. Psychiatric Services 65: 429-441.

Davidson, L., Bellamy, C., Kimberly, G. \& Miller, R. (2012) Peer support among persons with severe mental illnesses: a review of evidence and experience. World Psychiatry. 11(2): 123-8.

Davidson, L., Chinman, M. Sells, D. \& Rowe, M. (2006) Peer support among adults with serious mental illness: a report from the field. Schizophrenia Bulletin. 32(3): 443-450.

Davidson, L., Chinman, M., Kloos, B., Weingarten, R., Stayner, D. \& Tebes, J. K. (1999) Peer support among individuals with severe mental illness: a review of the evidence. Clinical Psychology Science and Practice. 6: 165-187.

Deegan, P. (1995) Coping with recovery as a journey of the heart. Psychiatric Rehabilitation Journal. 19: 91-7.

Deegan, P. E. (1988) Recovery: the lived experience of rehabilitation. Psychosocial Rehabilitation Journal. 11: 11-19.

Frost, B. G., Tirupati, S., Johnston, S. \& Conrad, A. (2017) An integrated recovery-oriented model (IRM) for mental health services: evolution and challenges. BMC Psychiatry. 17(2). DOI 10.1186/s12913-016-1939-8.

Gartner, A. \& Reissman, F. (1977) Self-help in the Human Services. San Francisco: Jossey-Bass.

Hunter, S. \& Ritchie, P. (eds)(2007) Co-production and Personalisation in Social Care: Changing Relationships in the Provision of Social Care. London: Jessica Kingsley. 
Jones, K. (1993) Asylums and After: A revised history of the mental health services: From the early $18^{\text {th }}$ century to the 1990s. London: Athlone.

Knapp, M. R. J., Cambridge, P., Thomason, C., Beecham, J., Allen, C., \& Darton, R. (1992). Care in the community: Challenge and demonstration. Aldershot: Ashgate.

Lawn, S., Smith, A., \& Hunter, K. (2008) Mental health peer support for hospital avoidance and early discharge: An Australian example of consumer driven and operated service. Journal of Mental Health. 17(5), 498-508.

Leamy, M., Bird, V., Le Boutillier, C., Williams, J. \& Slade, M. (2011) Conceptual framework for personal recovery in mental health: systematic review and narrative synthesis. British Journal of Psychiatry 199: 445-452.

McCranie, A. (2010). Recovery in Mental Illness: The Roots, Meanings, and Implementations of a 'New' Services Movement. In Pilgrim, D., Rogers, A. \& Pescosolido, B. (eds) The Sage Handbook of Mental Health and Illness. London: Sage: 471-89.

McDonald, A. (2006) Understanding Community Care: A guide for social workers. $\left(2^{\text {nd }}\right.$ edn) Basingstoke: Palgrave Macmillan.

Payne, M. (2014) Modern Social Work Theory. (4 ${ }^{\text {th }}$ edn) Basingstoke: Palgrave Macmillan.

Perring, C., Twigg, J. \& Atkin, K. (1990) Families Caring for people diagnosed as Mentally Ill: The literature re-examined. London: HMSO.

Pfeiffer, P. N., Heisler, M., Piette, J. D., Rogers, M. A., \& Valenstein, M. (2011). Efficacy of peer support interventions for depression: a meta-analysis. General Hospital Psychiatry. 33(1): 29-36.

Porter, R. (1987) A Social History of Madness: Stories of the Insane. London: Weidenfeld and Nicolson.

Proctor, N., Baker, A., Grocke, K. \& Ferguson, M. (2014) Human connectedness and the collaborative consumer narrative. In Proctor, N., Hamer, H. P., McGarry, D., Wilson, R. L. \& Froggatt, T. (eds) Mental Health: A person-centred approach. Melbourne: Cambridge University Press: 1-24.

Qureshi, H., Challis, D. \&Davies, B. (1989) Helpers in CaseManaged Community Care. Aldershot. Gower. 
Race, D. G. (ed.)(2003) Leadership and Change in Human Services: Selected Readings from Wolf Wolfensberger. London: Routledge.

Ramon, S. (1985) Psychiatry in Britain: Meaning and policy. London: Croom Helm.

Ramon, S. (1989) The value and knowledge bases of the normalization approach: implications for social work. International Social Work. 32(1): 11-23.

Renshaw, J., Hampson, R., Thomason, C., Darton, R., Judge, K. F., \& Knapp, M. R. J. (1988). Care in the community: The first steps. Aldershot: Gower.

Repper, J. (2013a) Peer Support Workers: A practical guide to implementation. London: Centre for Mental Health and Mental Health Network, NHS Confederation.

Repper, J. \& Carter, T. (2010) Using Personal Experience to Support Others with Similar Difficulties: A review of the literature on peer support in mental health services. London: Together for Mental WellBeing.

Simpson, E. L \& House, A, O. (2002) Involving Users in the delivery and evaluation of mental health services: systematic review. British Medical Journal. 325, 1265-8

Sledge, W. H., Lawless, M., Sells, D., Wieland, M., O'Connell, M. J., \& Davidson, L. (2011) Effectiveness of peer support in reducing readmissions of persons with multiple psychiatric hospitalizations. Psychiatric Services. 62(5): 541-4.

Solomon, P. (2004) Peer support/peer provided services: underlying processes, benefits, and critical ingredients. Psychiatric Rehabilitation Journal. 27(4): 392-401.

Stubbs, B., Williams, J., Shannon, J., Gaughran, F. \& Craig, T. (2016) Peer support interventions seeking to improve physical health and lifestyle behaviours among people with serious mental illness: A systematic review. International Journal of Mental Health Nursing. 25(6): 484-495.

Tew, J., Ramon, S., Slade, M., Bird, V., Melton, J. \& Le Boutillier, C. (2012) Social factors and recovery from mental health difficulties: a review of the evidence. British Journal of Social Work. 42 (3): 44340 . 
Trachtenberg, M., Parsonage, M., Shepherd, G. \& Boardman, J. (2013) Peer support in mental health care: is it good value for money? London: Centre for Mental Health.

Unsworth, C. (1979) The balance pf medicine, law and social work in mental health legislation, 1889-1959. In Parry, N., Rustin, M., \& Satyamurti, C. (eds) Social Work, Welfare and the State. London: Edward Arnold.

Watts, M. \& Higgins, A. (2017) Narratives of Recovery from Mental Illness: The role of peer support. London Routledge.

Willmott, P. (1986) Social Networks, Informal Care and Public Policy. London: Policy Studies Institute

Wolfensberger, W. (1972) The Principle of Normalisation in Human Services. Toronto: National Institute on Mental Retardation. 